\title{
Potential of genomic approaches in conservation of plant and animal biodiversity in Africa: A review
}

\author{
Fredrick Ojija ${ }^{1}$, Kafula Chisanga ${ }^{2}$, Sayuni P. Nasari ${ }^{3}$, Mikaila B.A. Garko ${ }^{4},{ }^{5}$ Nicolaus O. \\ Mbugi,
}

\author{
${ }^{1}$ Mbeya University of Science and Technology, Box 131, Mbeya, Tanzania \\ ${ }^{2}$ Zambia Agriculture Research Institute (ZARI), Mochipapa Research Station, Box 630090, Choma, Zambia \\ ${ }^{3}$ Stefano Moshi Memorial University College, Box 881, Moshi, Tanzania \\ ${ }^{4}$ Beyero University, PMB 3011, Kano, Nigeria \\ ${ }^{5}$ Mbeya University of Science and Technology, Box 131, Mbeya, Tanzania
}

\begin{abstract}
In Africa, status of biodiversity conservation of many plants and animals is questionable as this is considered to be caused by limited and lack of authentic information concerning genetic diversity. This has led to a considerable compromise of conservation decisions in Africa. As a result, lack of reliable information continues to cause a great effect on the long-term security of species of plants and animals. Current advancement in genomics has proved to play a vital role in conservation of plant and animal biodiversity. It produces genetic data that helps researchers to understand the interaction between ecosystem and organisms, also among organisms themselves. The information extracted from plants and animals via genomics techniques can be used to develop good approaches for biodiversity conservation. Despite its usefulness, there is a limited awareness on the application of potential genomics in plants and animals conservation in many developing countries, especially in Africa. The aim of this review is to raise awareness and catalyse the application of genomics techniques in rejuvenation and conservation of plants and animals in Africa. Precisely, the paper addresses the efficacy of potential genomics in plants and animals conservation; and seeks to show how Africa can benefit from genomics technology. About 62 peer-reviewed articles were reviewed. This current review has shown that genomics helps to identify good genes for fitness, and develops tools to monitor and conserve plants and animals biodiversity. The review recommends that regardless of the limitation of genomics application in biodiversity conservation in Africa, African researchers must consider using this technology for better conservation of plants and animals biodiversity.
\end{abstract}

Keywords- Biodiversity, Conservation genomics, Extinction genetic diversity, genetic tools, Natural variation.

\section{INTRODUCTION}

Despite being rich in biodiversity, Africa is experiencing a considerable loss of its plant and animal biodiversity (Muhumuza and Balkwill, 2013). While most developed countries have adopted Genomic technologies in an effort to conserve biodiversity, their use elusive in Africa (Lyantagaye, 2013; Muhumuza and Balkwill, 2013). Climate change coupled with other human induced factors further threaten plant and animals species of which many are at risk of extinction (Thomsen and Willerslev, 2015; Yule et al. 2013). Anthropogenic activities such as pollution, habitat destruction of habitats, overexploitation and introduction of alien invasive species are among the factors causing loss of plant and animal biodiversity (Dirzo et al. 2014; Thomsen and Willerslev, 2015). Preventing this loss of plant and animal biodiversity is a challenge that many countries in Africa face (Dirzo et al. 2014). Several conservation policies, agreements, declarations and strategies have been implemented to stop the causal loss process of plant and animal species. Abascal et al. (2016) reported that, even if all above mentioned threats are eliminated, certain species may fail to survive because of accumulation of genetic deterioration - a process whereby an endangered animal and plant species with a limited gene pool shrinks more and some individuals from the living population even die before having a chance to breed with others in their endangered low population (Abascal et al. 2016). As a consequence, such deterioration leads to losses in genetic diversity (the raw materials required for adaptation by natural selection), poor fertility and health, and a great prevalence of genetically determined abnormalities and disorders. Additionally, genetic defects may reduce semen quality and cause several other abnormalities, hence affecting the population.

From an ecological and socio-economic perspective, conservation of natural variation of plant and animal species is important (Mazzotti, 2014). There are benefits 
that may occur in some species as a result of natural variation, and other species can be valuable than others (Hoffmann et al. 2015). But anthropogenic pressure in the environment decreases natural variation of species, thus increasing life uncertainty of plants and animals in their habitats (De Vos et al. 2015; Godoy, 2016; Khan et al. 2016; Li et al. 2014). Anthropogenic disturbances in the environment are due to progress in technology and industrialization, increase in human population, global warming and other human related influences (Hoffmann et al. 2015; Yule et al. 2013). Prolonged exposure of organisms to anthropogenic activities causes loss of biodiversity (De Vos et al. 2015). Biodiversity conservation is the international political agreement agenda that emphasizes the management and conservation of plants and animals world-wide (Funk et al. 2012; Khan et al. 2016). However, the information about plants and animals biodiversity as well as genetic diversity in many places around the world is limited (De Cara et al. 2013; Hasbún et al. 2016).

The application of genomics for conservation of plant and animal population or biodiversity is known as conservation genomics (Garner et al. 2016; Grueber, 2015). It is the field of science that uses genomic data from thousands or tens of thousands of loci to address important questions for biodiversity conservation (Garner et al. 2016; Perry et al. 2012; Wamalwa et al. 2016). Compared to old conservation genetic methods that used 10-20 loci, conservation genomics is much more powerful (Gayral et al. 2013; McCormack et al. 2013; McMahon et al. 2014). The technique allows precise approximations of demographic parameters such as population size, variations in population size, and flow of gene (Du et al. 2016; Tian et al. 2017). It gives the opportunity to demonstrate adaptive genetic variation across real world (Hasbún et al. 2016). It is also possible to tell and describe the identity of plant and animal species, genetic diversity, hybridization level, effective population size and demographic history using genomic methods (Irizarry et al. 2016; Tian et al. 2017).

The total number of genetic characteristics in the genetic makeup of species refers to genetic diversity (Rao and Hodgkin, 2002), whereas, genetic variability is the variations of genetic characteristics in the population (Yazici and Bilir, 2017). Genetic diversity is very important for species existence because it helps populations to adapt to different environmental changes. Because of the development of genomic methods, it is possible to assess genetic variability (Hintzsche et al. 2016) and improve plant and animal conservation and restoration (Miller et al. 2012). Ecologists and biologists can understand the evolutionary tree of life (Hasbún et al. 2016) and provide measures for biodiversity conservation using genomic tools (Funk et al. 2012). They can solve biodiversity conservation and restoration difficulties using genomic techniques (Miller et al. 2012). Moreover, they can also influence conservation policy and strategies (Khan et al. 2016).

\section{BIODIVERSITY, CONSERVATION AND GENOMICS}

Genomics is defined as the branch of science in the field of molecular biology which deals with the function, evolution, structure and mapping of genomes (Kadakkuzha and Puthanveettil, 2013; Lyantagaye, 2013). It is concerned with the study of genomes and their interaction with the environment (Ekblom and Wolf, 2014; Reportlinker, 2013). Roderick (1986) defined the term genomics as a science discipline which refers to the mapping, sequencing, as well as analysis of the genome (Khan, 2016; Xu, 2012). A genome is whole set of deoxyribonucleic acid (DNA) within a single cell of an organism, or a complete set of chromosomes that decides an organism (Renaut et al. 2012; Khan et al. 2016). Genetic data generated from genomics study can help researchers and ecologists understand the interaction between ecosystem and organisms (Funk et al. 2012). Understanding this interaction is critical in developing a better approach for conservation (Hongbo et al. 2015; Lyantagaye, 2013; Toro et al. 2014). Furthermore, it may help finding out how living organisms differ between and within species as well as how they differ from each other (Reportlinker, 2013). Genomics potentially allows biologists or scientists to study genes over time and to test the genetic variability of any form of life, from prokaryotes to eukaryotes (Tian et al. 2017). One of the most evident findings of genomics is the ability to explain how much is shared between organisms (Xu, 2012). Different forms of life including diverse microorganisms, animals, plants, their ecosystems and the genes they contain on the earth is called biodiversity (Khan et al. 2016; McCarthy et al. 2012; Rawat and Agarwal, 2015). On the other hand, Rao and Hodgkin (2002) defined biodiversity as the variation existing in all species of animals and plants, their genetic material and the ecosystems in which they occur. Three levels of biodiversity are characterized within an area, biome or planet (Fig. 1). These are ecosystem diversity, genetic diversity and species diversity (Khan et al. 2016; Rawat and Agarwal, 2015; Nuijten et al. 2016). Ecosystem diversity means different habitats, ecological process and biotic communities within the biosphere (McMahon et al. 2014). Species diversity is defined as the variety of species within an ecosystem, while, genetic diversity refers to the variation within species and population (Nuijten et al. 2016) or variation in genes and genotype 
(Rao and Hodgkin, 2002). Despite the fact that genetic diversity is important for species adaptation and survival, it is also a major component in the ecosystem (Rawat and Agarwal, 2015). Existence and evolutionary success of many living organisms depend on the genetic diversity (Gülcü and Bilir, 2017; McMahon et al. 2014). Thus, biodiversity can also mean the variability within and between species, and between ecosystems (McCarthy et al. 2012: McMahon et al. 2014). In both genetics and genomics, diversity is recognized as one of the most fundamental levels of biodiversity together with ecosystem diversity, species diversity and community diversity (McMahon et al. 2014).

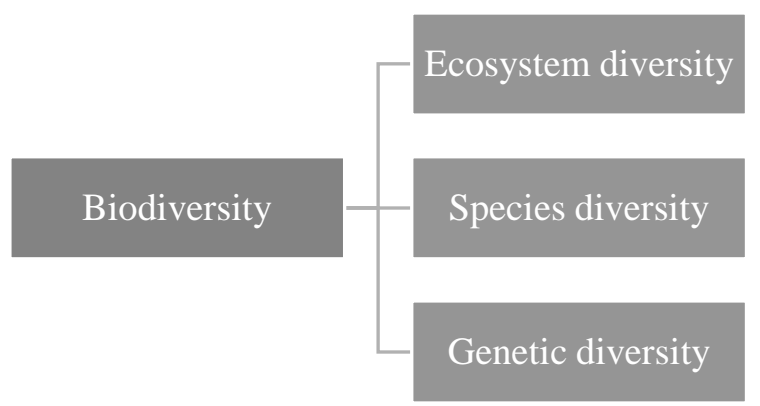

Fig.1: Three levels of biodiversity within a biome

There are several biotic and abiotic factors that have negative impacts on biodiversity (Bahrndorff et al. 2016). These factors are shown in Fig. 2, and include predation, parasitism, competition, diseases, and separation due to human actions, habitat alteration, climatic changes and natural catastrophes (Hoffmann et al. 2015; Khan et al. 2016), introduction of exotic species, destruction of natural habitat as well as killing of natural components of a population (IUCN, 2015; Mazzotti, 2014). These factors not only cause decrease in biodiversity of plants and animals, but also cause extinction of biodiversity of some species (De Vos et al. 2015). Most of these factors provoke displacement of species from their natural habitats, retreating, and completely vanish from the wilderness (Mazzotti, 2014). Because of these threats, several studies have suggested the use of genomic tools as effective methods for conservation of plants and animals biodiversity (Aravanopoulos, et al. 2015; De Vos et al. 2015; Khan et al. 2016; IUCN, 2015; Lyantagaye, 2013). The main concern of researchers is to maintain rare and endangered species of plants and animals via genomic methods (Aravanopoulos, et al. 2015; Nuijten et al. 2016; Shafer et al. 2015). Therefore, based on genomic studies there are genomic conservation tools developed in order to stop dwindling of biodiversity (Fig. 3).

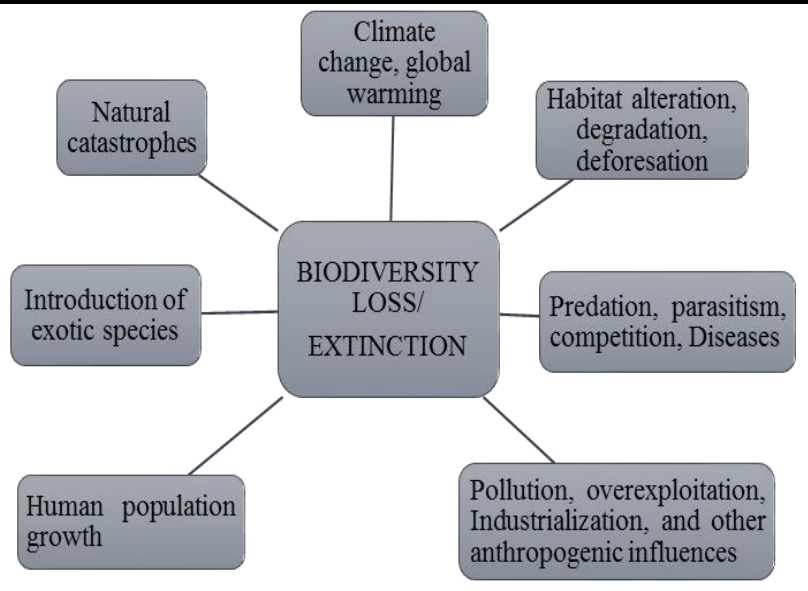

Fig. 2: Summarized factors that have negative impacts on biodiversity

Currently, the most used genetic tools in plants and animals include amplified fragment length polymorphism (AFLP), DNA and RNA sequence analysis, and DNA finger printing, microsatellites, minisatellites, and random amplification of polymorphic DNA (RAPD), random fragment length polymorphism (RFLP), single strand conformation polymorphism (SSCP) and single nucleotide polymorphisms (SNPs). Summary of these tools is shown in Fig. 3. Current individuals' DNA or historic DNA is used by these tools to analyse genetic variation in species or population (Khan et al. 2016). Because of the development in high throughput next generation sequencing, other tools are used in population and conservation genomic in forest and fruit tree. (Aravanopoulos et al. 2015). Numerous techniques and tools exist that use genomic methods to conserve plant and animal biodiversity. McCormack et al. (2013) emphasize that, if there is a need to apply genomics in conservation such as in endangered plant and animal species, the genomes of these species must be sampled at considerable densities and with extra markers.

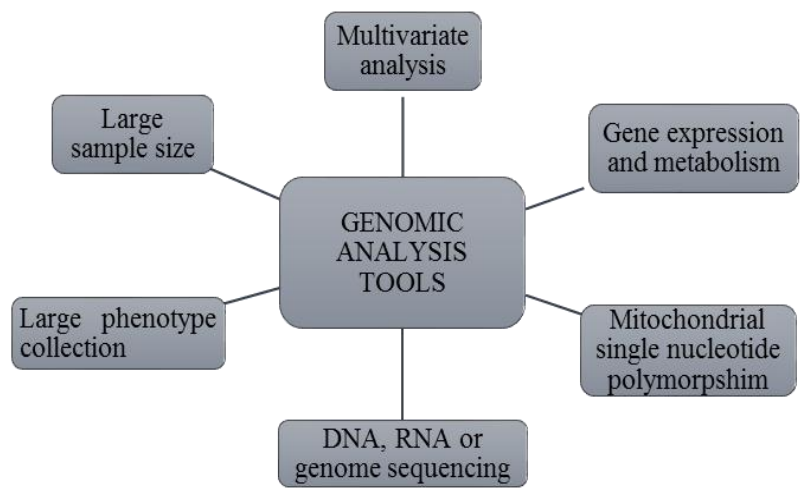

Fig. 3: Summary of genomic tools used to detect genetic variations in plants and animals 


\section{WHY GENOMICS?}

Understanding the genetic structure and composition of plants and animals in their habitat is important for developing successful management strategies for their conservation. Declining of global biodiversity of plants and animals attract attention of biologists and ecologists towards conservation (Aravanopoulos, et al. 2015; Nuijten et al. 2016; Rutledgea et al. 2012; Catchen et al. 2013; Hoffmann et al. 2015). In order to reduce loss of plant and animal biodiversity, researchers have been using genomic methods and techniques (McMahon et al. 2014). Genomic methods allow collection of extensive genetic information of phenotypic and ecological data from many species in numerous populations and individuals (Hohenlohe et al. 2012; Khan et al. 2016; Trinh et al. 2017). These genetic data are used to identify the signatures of selection and adaptive genetic variation on a complete genome scale (Catchen et al. 2013). The data can also be used to provide a possibility to differentiate nearly related but adaptively different populations (Hohenlohe et al. 2012). Further, Perry et al. (2012) claimed that, it is possible to gather huge amounts of data and sequence any species at moderate effort than previous due to advancement of genomics technology. Genomics plays an important role in conservation of plants and animals (Gardner et al. 2016; Godoy, 2016; Khan et al. 2016; McMahon et al. 2014). It aids to determine the genome segments responsible for adaptation, and improve our knowledge on microevolution through a better understanding of positive mutation, selection and recombination (Funk et al. 2012; Gülcü and Bilir, 2017; Trinh et al. 2017). It helps to identify essential genes for fitness and eventually develops modern monitoring tools for endangered plant and animal species (Godoy, 2016). Development of potential genomic tools has enabled studies of population structure, current demographic events and genetic variations in threatened species of plants and animals (Grueber, 2015). With advanced genomics tools it is possible to detect harmful mutations in the genes for metabolism, functions, immunity and in any part of living organism, plants and animals (Grueber, 2015; Khan et al. 2016). Techniques and tools of genomics are used to detect variations linked with conservation and population structure from the genome of various species (Khan et al. 2016; Mcmahon et al. 2014). Genomics analysis tools give researchers a deeper level of understanding the organisms in their environments (Funk et al. 2012; Gardner et al. 2016; Jones et al. 2013), and to track the movements of individual organisms (Simpson et al. 2017). For example, more than 3000 individual of humpback whales (Megaptera novaeangliae) have been distinguished using genetic fingerprints obtained from skin samples (WCS, 2017). This used genomics techniques by carefully comparing selected markers in the DNA of thousands of whales. According to WCS (2017), this technique is important for monitoring the movements of the whales from the South Atlantic to the Indian oceans, and conservation of the whale populations. Similarly, genomics tools like this can help to establish whether how and when the interaction of different species of the population occurs. Furthermore, a study on water voles in Scotland to understand if their survival is threatened by mink was done using DNA microsatellite markers, the DNA study showed that the mink is not a threat to the population of water voles because a result revealed high genetic mixing levels (Melis et al. 2013). In addition, the DNA studies on Pipistrelle bats in UK confirmed that there are two species but not a single species. Furthermore, Aravanopoulos et al. (2015) claimed that, advanced genomics accelerate the rate of conservation genomics in forest plants. This is because of the development in high throughput next generation sequencing capabilities.

In the absence of phenotypic information, the genomics has made possible to identify population with adaptive compatibilities on the basis of genetic data (Tian et al. 2017; Trinh et al. 2017). Ecologists and biologists have been trying to discover genes that support local adaptation in certain species in ecosystems. Understanding the genetic architecture of local adaptation is fundamental to defining conservation units, determine conservation priorities and design restoration programmes for threatened or endangered plant and animal species (Miller et al. 2012). Catchen et al. (2013) opined that, identification of genetic diversity is important for the adaptation of populations at their local habitats, and it can be used to design a biodiversity conservation framework. For example, the population with specific adaptive alleles can be identified and used to supplement the endangered population or reintroducing species into the habitat in which the natural population has vanished (Simpson et al. 2017). The loss of genetic diversity and inbreeding accumulation due to fragmentation and decrease of population may compromise the viability of population (Casas-Marce et al. 2013). An example of organism showing this is the Iberian lynx (Lynx pardinus) which is in the edge of extinction (Godoy, 2016). Mitochondrial sequences and 36 microsatellite markers were used to evaluate the current genetic status of the Iberian lynx and to assess the genetic signatures of its past history (Abascal et al. 2016; Casas-Marce et al. 2013). Species' mitochondrial diversity was found to be very low with only two haplotypes; furthermore, Abascal et al. (2016) and Godoy (2016) showed that the levels of genetic diversity at microsatellite markers were very low in both 
remnant populations. Yet, genetic differentiation between the two populations was high. By using genomic tools, Abascal et al. (2016), Casas-Marce et al. (2013) and Godoy, (2016) concluded that, the present genetic patterns in the L. pardinus are because of the result of its recent decline and fragmentation. Therefore, conservation measures can be taken to stop further population fragmentation and decline. Although a recovery of endangered species of plants and animals is hindered by excessive population decline, genetic erosion can make it more badly (Godoy, 2016). In order to appreciate the patterns of genomic erosion and how this affect species viability of plants and animals we need to use genomics tools. This is because these tools help to conserve species, and contribute to save species from extinction (Aravanopoulos et al. 2015; Karolchik et al. 2014). Development of genomics has resulted into increase in the number of species with whole-genome sequence data (Ellegren, 2014; Grueber, 2015; Rutledgea et al. 2012). This has made availability of genome resources to most endangered plant and animal species (Ellegren, 2014; Grueber, 2015; Karolchik et al. 2014). Conservation of plants and animals is growing and promises to modernise the population genetics field due to the use of genomewide single nucleotide polymorphisms (Rutledgea et al. 2012). In some species, a relationship between environmental characteristics and the distribution of genotypes can be detected using genomics technology, showing the importance of natural selection as the main source of differentiation (Hasbún et al. 2016).

Considering the species richness of Africa, including many endangered species, it is imperative to adopt usage of genomic methods for biodiversity conservatory purposes. Since genomic techniques and tools are becoming cheaper and more accessible (McCormack et al. 2013), biologists and researchers in Africa can use these tools to conserve and manage plant and animal biodiversity. Furthermore, the use of genomic analysis tools can be used to assess and track the distribution of threatened and endangered plants and animals (Bowden et al. 2012; Steiner et al. 2013). This makes conservation of plant and animal biodiversity very easier, and thus reducing the rate of biodiversity loss and even extinction from the wild (Hongbo et al. 2015). Genomics has enabled studies of how climate change has limited biodiversity by looking at DNA of ancient preserved specimens of plants and animals to understand, and how biodiversity has changed with time (Fitzpatrick et al. 2012; Johnson and Koepfli, 2014; McMahon et al. 2014; Miller et al. 2012). These techniques can further inform sound policy decisions for conservation and management of wildlife biodiversity against climate change effect. It is apparent, therefore that accurate usage of genomic tools can result into considerable conservation of Africa's biodiversity, to sustainably meet plant and animal species' demands for future generations.

\section{CONCLUSIONS}

This review has demonstrated that biologists, conservationists, ecologists and researchers should appreciate the conservation benefit resulting from genomic methods especially for plants and animals. Advanced genomics plays a vital role in biodiversity conservation and produces genetic data that help researchers to know the interaction between ecosystem and organisms, and among organisms themselves. The information extracted from them through genomic techniques can be used to develop methods for biodiversity conservation. Moreover, the development of conservation genomic tools can enhance our understanding of the genetic variation and structure of plants and animals. Researchers in developing countries are highly encouraged to use the advanced genomic methods to improve biodiversity conservation sector and reduce loss of plants and animals. Genomic conservation is very crucial as this is key to understanding the genetic structure, relationships of phylogenetic, causes and reasons for loss of genetic diversity in plants and animals. Finally, if well utilized, genomic methods can guide decision making in our conservation strategies and policies in Africa.

\section{ACKNOWLEDGEMENTS}

Authors would like to thank Cecilia M. Leweri, Japheth K. Ng'etich, and Rowland Kamanga for helping in structuring and editing of this manual script.

\section{REFERENCES}

[1] Abascal, F., Corvelo, A., and Cruz, F. et al. (2016) Extreme genomic erosion after recurrent demographic bottlenecks in the highly endangered Iberian lynx. Genome Biol. 17:251. doi: 10.1186/s13059-016-1090-1.

[2] Aravanopoulos, F.A., Ganopoulos, I., and Tsaftaris, A. (2015) Population and conservation genomics in forest and fruit trees. Adv. in Bot. Res. 74: 125-155. doi.org/10.1016/bs.abr.2015.04.001.

[3] Bahrndorff, S., Alemu, T., Alemneh, T., and Nielsen, J.L. (2016) The microbiome of animals: Implications for conservation biology. Int. J. of Genom. ID 5304028. doi.org/10.1155/2016/5304028.

[4] Bowden, R., MacFie, T. S., and Myers, S. et al. (2012) Genomic tools for evolution and conservation in the chimpanzee: Pan troglodytes ellioti is a genetically distinct population. PLoS Genetics 8:e1002504. 
[5] Casas-Marce, M., Soriano, L., López-Bao, J.V., and Godoy, J.A. (2013) Genetics at the verge of extinction: insights from the Iberian lynx. Mol. Ecol. 22(22): 5503-15. doi: 10.1111/mec.12498.

[6] Catchen, J., Bassham, S., and Wilson, T. et al. (2013) The population structure and recent colonization history of Oregon three spine stickleback determined using RAD-seq. Mol. Ecol. 22(11): 2864-2883. doi:10.1111/mec.12330.

[7] De Cara, M.A.R., Villanueva, B., Toro, M.A., and Fernandez, J. (2013) Using genomic tools to maintain diversity and fitness in conservation programmes. Mol. Ecol. 22(24): 6091-6099.

[8] De Vos, J.M., Joppa, L.N., and Gittleman, J.L. et al. (2015) Estimating the normal background rate of species extinction. Conserv. Biol. 29 (2): 452-462.

[9] Dirzo, R., Young, H.S., and Galetti, M. et al. (2014) Defaunation in the anthropocene. Sci. 345: 401-406. doi.org/10.1126/science.1251817.

[10] Du, H., Fang, R., and Pan, T. et al. (2016) Comparative genomics analysis of two different virulent bovine Pasteurella multocida Isolates. Int. J. of Genom. ID 4512493. doi.org/10.1155/2016/4512493.

[11]Ekblom, R., and Wolf, J.B.W. (2014) A field guide to whole-genome sequencing, assembly and annotation. Evolutionary Appl. 7: 1026-.1042. doi:10.1111/eva.12178. 6.

[12]Ellegren, H. (2014) Genome sequencing and population genomics in non-model organisms. Trend. in Ecol. and Evol. 29:51-63.

[13] Hoffmann, A., Griffin, P., Dillon, S. et al. (2015) A framework for incorporating evolutionary genomics into biodiversity conservation and management. Climate Change Responses, 2:1. DOI 10.1186/s40665-014-0009-x.

[14] Hongbo, S., Sixue, C., and Brestic, M. (2015) Environment-Living organism's interactions from physiology to genomics. Int. J. of Genom. ID 270736. doi.org/10.1155/2015/270736.

[15]Funk, W.C., McKay, J.K., Hohenlohe, P.A., Allendorf, F.W. (2012) Harnessing genomics for delineating conservation units. Trend. in Ecol. and $\begin{array}{llll}\text { Evolu. } & 27 & \text { (9): }\end{array}$ doi.org/10.1016/j.tree.2012.05.012.

[16] Fitzpatrick, B. M., Fordyce, J.A., Niemiller, M.L., and Reynolds, R.G. (2012) What can DNA tell us about biological invasions? Biol. Inv. 14:245-253.

[17] Garner, B.A., Brian K. H., Amish, S.J., et al. (2016) Genomics in conservation: Case studies and bridging the gap between data and application. Trend. in Ecol. and $\quad$ Evol. 31(2): 81-83. doi.org/10.1016/j.tree.2015.10.009.
[18] Gayral, P., Melo-Ferreira, J., and Glemin, S. et al. (2013) Reference-free population genomics from next-generation transcriptome data and the vertebrate-invertebrate gap. PLoS Genetics, 9:e1003457.

[19] Godoy, J.A. (2016) Genomics and the conservation of species: insights from the Iberian lynx. https://blogs.biomedcentral.com/on-

biology/2016/12/14/genomics-conservation-speciesinsights-iberian-lynx/. Accessed 27 February 2017.

[20] Grueber, C.E. (2015) Comparative genomics for biodiversity conservation. Computational and Structural Biotech. J. 13: 370-375.

[21] Gülcü, S., and Bilir, N. (2017) Growth and survival variation among Scots Pine (Pinus sylvestris L.) Provenances. Int. J. of Genom. ID 1904623. doi.org/10.1155/2017/1904623.

[22] Hintzsche, J.D., Robinson, W.A., and Tan, A.C. (2016) A survey of computational tools to analyze and interpret whole exome sequencing data. Int. J. of Genom. ID 7983236. doi.org/10.1155/2016/7983236.

[23] Hohenlohe, P.A., Catchen, J., and Cresko, W.A. (2012) Population genomic analysis of model and nonmodel organisms using sequenced RAD tags. Methods Mol. Biol. 2012b; 888:235-260.

[24] Hasbún, R., González,J., Iturra, C., Fuentes, G., Alarcón, D., and Ruiz, E. (2016) Using GenomeWide SNP discovery and genotyping to reveal the main source of population differentiation in Nothofagus dombeyi (Mirb.) Oerst. In Chile. Int. J. of Genom. ID 3654093. doi.org/10.1155/2016/3654093.

[25] Irizarry, K.J.L., Bryant, D., and Kalish, J. et al. (2016) Integrating genomic data sets for knowledge discovery: An informed approach to management of captive endangered species. Int. J. of Genom. ID 2374610. doi.org/10.1155/2016/2374610.

[26] IUCN (2015), The IUCN red list of threatened species. http:// www.iucnredlist.org/current-news. Accessed 22 February 2017.

[27] Jiang, P., Zhang, P., Zhang, X., and Ma, H. (2017) Genetic diversity and association analysis for solvent retention capacity in the accessions derived from soft wheat ningmai 9. Int. J. of Genom. ID 2413150. doi.org/10.1155/2017/2413150.

[28] Jones, F.C, Grabherr, M.G, and Chan, Y.F. et al. (2012) The genomic basis of adaptive evolution in three spine sticklebacks. Nature. 484: 55-61.

[29] Johnson, W.E., and Koepfli, K. (2014) The role of genomics in conservation and reproductive sciences. Advan. in Exp. Med. and Biol. 753: 71-96. 
[30] Kadakkuzha, B.M, and Puthanveettil, S.V. (2013) Genomics and proteomics in solving brain complexity. Mol. BioSyst. 9: 1807-1821.

[31] Karolchik, D., Barber, G.P., Casper, J. et al. (2014) The UCSC genome browser database: 2014 update. Nucleic Acids Res. 42:D764-70.

[32] Khan, S., Nabi, G., Ullah, M.W., et al. (2016) Overview on the role of advance genomics in conservation biology of endangered species. Int. J. of Genom. ID 3460416. doi.org/10.1155/2016/3460416.

[33] Li, S., Li, B., Cheng, C, et al. (2014) Genomic signatures of near extinction and rebirth of the crested ibis and other endangered bird species. Genome Biology, 15(12): 557-572.

[34] Lyantagaye, S.L. (2013) Current status and future perspectives of bioinformatics in Tanzania. Tanz. J. Sci. 39.

[35] Mazzotti, .F.J. (2014) The Value of Endangered Species: The importance of conserving biological diversity, wildlife ecology and conservation department, University of Florida, Cooperative Extension Service, Institute of Food and Agriculture Sciences, UF/IFAS Extension, Gainesville, Fla, USA, 2014.

[36] McCarthy, D. P., Donald, P.F., Scharlemann, J. P. W., et al. (2012). Financial costs of meeting global biodiversity conservation targets: current spending and unmet needs. Sci. 338:946-949.

[37] McCormack, J. E., Hird, S.S., Zellmer, A.J., et al. (2013) Applications of next-generation sequencing to phylogeography and phylogenetics. Mol. Phylog. and Evol. 66:526-538.

[38] McMahon, B.J., Teeling, E.C., Höglund, J. (2014) How and why should we implement genomics into conservation? Evol. App. 7: 999-1007.

[39] Melis, C., Borg, A.A., Jensen, H., et al. (2013) Genetic variability and structure of the water vole Arvicola amphibius across four metapopulations in northern Norway. Ecol. Evol. 3(4): 770-778. doi: 10.1002/ece3.499.

[40] Miller, M.R., Brunelli, J.P., Wheeler, P.A., et al. (2012) A conserved haplotype controls parallel adaptation in geographically distant salmonid populations. Mol. Ecol. 21: 237-249. doi: 10.1111/j.1365-294X.2011.05305.x.

[41] Miller, W., Schuster, S.C., Welch, A.J., et al. (2012) Polar and brown bear genomes reveal ancient admixture and demographic footprints of past climate change. Proceedings of the National Acad. of Sci. of the U.S.A. 109: E2382-E2390.

[42] Muhumuza, M., and Balkwill, K. (2013) Factors Affecting the Success of Conserving Biodiversity in National Parks: A Review of Case Studies from
Africa. Int. J. of Biod. ID 798101. doi.org/10.1155/2013/798101.

[43] Muthiah, A., Keller, S.R., and Lee, J.K. (2017) Module Anchored Network Inference: A Sequential Module-Based Approach to Novel Gene Network Construction from Genomic Expression Data on Human Disease Mechanism, Int. J. of Genom. ID 8514071. doi.org/10.1155/2017/8514071.

[44] Nuijten, R.J.M., Bosse, M., Crooijmans, R.P.M.A., et al. (2016) The Use of Genomics in Conservation Management of the Endangered Visayan Warty Pig (Sus cebifrons). Int. J. of Genom. ID 5613862. doi.org/10.1155/2016/5613862.

[45] Perry, G. H., Louis, E.E.J., Ratan, A., et al. (2012) Aye-aye population genomic analyses highlight an important center of endemism in northern Madagascar. Proceedings of the National Acad. of Sci. of the U.S.A. 110 (15): 110:5823-5828. doi: 10.1073/pnas.1211990110.

[46] Rao, V.R., and Hodgkin, T. (2002) Genetic diversity and conservation and utilization of plant genetic Resources. Plant Cell, Tissue and Organ Culture 68: $1-19$.

[47] Rawat, U.S., and Agarwal, N.K (2015) Biodiversity: concept, threats and conservation. Env. Conserv. J. 16: 19-28.

[48] Renaut, S., Maillet, N., Normandeau, E., et al. (2012) Genome-wide patterns of divergence during speciation: the lake whitefish case study. Phil. Trans. of R. Soci. 367:354-363. doi:10.1098/rstb.2011.0197.

[49] Reportlinker (2013) Genomics Industry: Bioinformatics Market by Sector (Molecular Medicine, Agriculture, Research and Forensic), Segment (Sequencing Platforms, Knowledge Management Tools and Data Analysis Services) and Application (Genomics, Proteomics and Drug Design), Global Forecasts to 2017. http://www.reportlinker.com. Accessed 18 February 2017.

[50] Rutledgea, L.Y., Wilsona, P.J., Klütscha, C.F.C., et al. (2012) Conservation genomics in perspective: A holistic approach to understanding Canis evolution in North America. Biol. Conserv. 155: 186-192. doi.org/10.1016/j.biocon.2012.05.017

[51] Shafer, A. B. A., Wolf, J. B. W., Alves, P. C., et al. (2015) Genomics and the challenging translation into conservation practice. Trend. in Ecol. and Evol. 30(2): 78-87.

[52] Steiner, C.C., Putnam, A.S., Hoeck, P.E.A., and Ryder, O.A. (2013) Conservation genomics of threatened animal species. Ann. Rev. of Animal Biosci. 1: 261-281. 
[53] Tian, W., Paudel, D., Vendrame, W., and Wang, J. (2017) Enriching Genomic Resources and Marker Development from Transcript Sequences of Jatropha curcas for Microgravity Studies. Int. J. of Genomics. ID 8614160. doi.org/10.1155/2017/8614160.

[54] Thomsen, P.F., and Willerslev, E. (2015) Environmental DNA - An emerging tool in conservation for monitoring past and present biodiversity. Biol. Conserv. 183: 4-18.

[55] Trinh, H., Nguyen, K.T., Nguyen, L.V., et al. (2017) Whole-Genome characteristics and polymorphic analysis of Vietnamese rice landraces as a comprehensive Information resource for markerassisted selection. Int. J. of Genom. ID 9272363. doi.org/10.1155/2017/9272363.

[56] Toro, M.A., Villanueva, B., and Fernández, J. (2014) Genomics applied to management strategies in conservation programmes. Livest. Sci. 166: 48-53. doi.org/10.1016/j.livsci.2014.04.020.

[57] Simpson, S.D., Ramsdell, J.S., Watson, W.H., and Chabot, C.C. (2017) The draft genome and Transcriptome of the Atlantic Horseshoe Crab, Limulus polyphemus. Int. J. of Genom. ID 7636513. doi.org/10.1155/2017/7636513.

[58] Wamalwa, E.N., Muoma, J., and Wekesa, C. (2016) Genetic diversity of Cowpea (Vigna unguiculata (L.) Walp.) Accession in Kenya gene bank based on simple sequence repeat markers. Int. J. of Genom. ID 8956412. doi.org/10.1155/2016/8956412.

[59] WCS (2017) Wildlife Conservation Society. Massive genetic study of humpback whales to inform conservation assessments: Study confirms need to protect unique humpback whales in Arabian Sea. www.sciencedaily.com/releases/2017/01/170109133 950 (Accessed 22 Feb. 2017).

[60] Xu, Y. (2012) Molecular plant breeding, in molecular breeding tool: Omics and Arrays, p 68, CABI.

[61] Yazici, N., and Bilir, N. (2017) Aspectual fertility variation and its effect on gene diversity of seeds in natural stands of Taurus Cedar (Cedrus libani A. Rich.). Int. J. of Genom. ID 2960624. doi.org/10.1155/2017/2960624.

[62] Yule, J., R. Fournier, R. and Hindmarsh, P. (2013) Biodiversity, extinction, and humanity's future: the ecological and evolutionary consequences of human population and resource use. Humanit. 2 (2): 147159. 